$16^{\text {th }}$ International Conference on

AEROSPACE SCIENCES \& AVIATION TECHNOLOGY, $\boldsymbol{A S A T}$ - 16 - May 26 - 28, 2015, E-Mail: asat@ mtc.edu.eg Military Technical College, Kobry Elkobbah, Cairo, Egypt Tel : +(202) 24025292 - 24036138, Fax: +(202) 22621908

\title{
Vacuum Effect on Spacecraft Structure Materials
}

\author{
Ahmad Anwar ${ }^{*}$, Marta Albano ${ }^{\dagger}$, Gamal Hassan ${ }^{1}$, Andrea Delfini ${ }^{\ddagger}$, \\ Fabrizo Volpini ${ }^{\S}$, Mario Marchetti ${ }^{\text {III }}$, and Dalia Elfiky\#
}

\begin{abstract}
:
In the vacuum deep space, outgassing has contributed to degraded mechanical performance of composite materials used in spacecraft. Three types of polymer based material we concerned on this study epoxy resin with carbon fiber, glass fiber, and Kevlar, which manufactured by hand lay-up method without autoclave curing which is a commercial method with low cost production. These materials have been widely used in satellite structures. The forth material is polyamide which is a commercial thin sheet layer used in multilayer insulation for spacecraft protection against space environment. The advantages of these materials considered as their high specific stiffness, near-zero coefficients of thermal expansion (CTE) and dimensional stabilities make them uniquely suited for applications in low specific weight environment.

The materials screening and selection will be discussed according to the total mass loss, the dimensions stability, and collected volatile condensed materials resulted from outgassing test for the different materials types.
\end{abstract}

Keywords: Vacuum, outgassing, polymers, glass fiber, carbon fiber, Kevlar, polyimide composite materials.

\section{Nomenclature:}

ASTM.

ECSS

FTIR

CVCM.

RML

CTE

TML

WVR.

LEO.

MLI.
American Society for Testing and Materials

European Cooperation for Space Standardization

Fourier Transform Infra-Red

Collected Volatile Condensable Material

Regained Mass Loss

Coefficient of Thermal Expansion

Total Mass Loss

Water Vapor Regained

Low Earth Orbit

Multi Layer Insulator

\footnotetext{
*Egyptian Armed Forces, msc.a.anwar@ gmail.com .

†Researcher, Sapienza University of Rome, marta.albano@uniroma1.it .

${ }^{1}$ Professor, National institute for Standards, gamalhassan65@hotmail.com

*Researcher, Sapienza University of Rome, andrea.delfini@ uniroma1.it.

${ }^{\S}$ Researcher, Sapienza University of Rome, fabrizio.volpini@uniroma1.it.

IProfessor, Sapienza University of Rome,mario.marchetti@uniroma1.it.

"Researcher,National Authority for Remote Sensing and Space Science,delfiky@ narss.sci.eg.
} 


\section{Introduction}

The spacecraft is exposed to different environmental threats which are not present at the earth surface. These threats are varies by the variation of the spacecraft altitude. The environmental threats cause many effects such as spacecraft material degradation and contamination. Vacuum is one of the space environmental threats which create three problems for spacecraft, [outgassing, cold welding, and heat transfer].

The vacuum level is mainly depends on the mission design especially the spacecraft altitude, most of the remote sensing spacecraft's mission lies between $200-1000 \mathrm{Km}$ height which called Low Earth Orbit (LEO). The vacuum at LEO is typically $10^{-9}-10^{-11}$ Torr outside the spacecraft and $10^{-6}-10^{-7}$ Torr inside spacecraft. [5] The materials tested in this study locate in the external spacecraft's structure which considered far away from the sensitive elements.

Composite and polymeric materials are widely used in space applications. These materials are used in many components in the spacecraft as structural, thermal and electrical components.

The main advantages of these materials which induced it to be widely used in space are their high specific stiffness, near-zero coefficients of thermal expansion (CTE) and dimensional stabilities.

This study concentrates on three composite materials carbon fiber, glass fiber and Kevlar which are used in spacecraft structure. These materials recently formed most of the spacecraft structure parts. They are space qualified but they are very expensive.

In this study a commercial manufacturing method is performed and tested to prove that these materials can be used in space with that manufacturing method.

This paper concerns about the outgassing as sever vacuum effect. The gases escaped out of the spacecraft materials due to the outgassing process occurred at elevated temperature could form a delicate layer of coating covers the optical sensors lenses or cause arc in the electronic components.

The outgassing process occurs mostly in polymeric materials which cause loss of dimension stability, structure distortion, surface contamination, and change in properties. Outgassed materials face a sever deterioration in the absorptance and transmittance. [1,2]

Selecting of material for spacecraft is highly affected by vacuum condition. The most important effect of vacuum is outgassing which is defined as the release of gaseous spices from the specimen under high vacuum conditions. [7]

The performances of the materials are degraded by the outgassing according to the following:

First, the gasses comes out of the material can be harmful especially to the optical surfaces and solar cells, these surfaces can be covered by the condensed gasses from the outgassed material. Second, the sensitive instruments may be affected by a cloud which is formed by the outgassed material. Third, the thermal control surfaces may be degraded by the molecular contamination releases by the outgassed materials. Finally, the polymeric materials faced a material properties change due to the outgassing process that causing volatile products. Dealing with the outgassing should be in advance during the materials design stages selecting the proper material which is suitable for use in space. The space materials screening is performed in accordance with the ECSS-Q-ST-70-02C or ASTM-E595 standard procedures. The criteria used for the acceptance and rejection of materials is determined by the user and based upon specific component and system requirements. Collected volatile condensable material (CVCM), total mass loss (TML), and water vapor regained (WVR). Historically, TML of $1.00 \%$ and CVCM of $0.1 \%$ have been used as screening levels for rejection of spacecraft materials. 


\section{Experiment}

\subsection{Sample preparation}

Composite materials with Epoxy based matrix are manufactured using hand layup process cured in room temperature without auto-clave facility, which is considered as a commercial material and non-expensive method compared with the auto-clave curing method. Auto-clave method is used to remove humidity from the manufacturing materials. A bidirectional ply used in the sheet fabrication. The laminated composite panels were fabricated by stacking multiple layers fabric. All panels for fabricating test specimens used in this study were laminates with the lay-up sequences. The number of plies specified to meet the required sheet thicknesses from 1.5 to 2.5 $\mathrm{mm}$ depended on the test standards adopted for each test.

The sample materials are made from commercial constituents, theses constituents have the same matrix with varies fabrics. The matrix based on an Epoxy resin "EpoLAM 5015" mixed with the epoxy hardener "EpoLAM 5014" with a mixing ratio 100:34 by weight.

The first material used in this study made from epoxy and carbon fabric used in aerospace industry an AMOCO made named (Thornel 300). The second one made from commercial Glass cloth used in aerospace industry, S - glass which has the highest stiffness and strength. The third is consists of Kevlar fabric used in aerospace industry. The forth material is polyamide which used in spacecraft multilayer insulation (MLI) manufacturing, MLI used in spacecraft protection from space radiation and thermal effect, the polyamide used in space is Kepton. A commercial sheet of polyamide (Artilon) which will be tested in this study is not usually used in space.
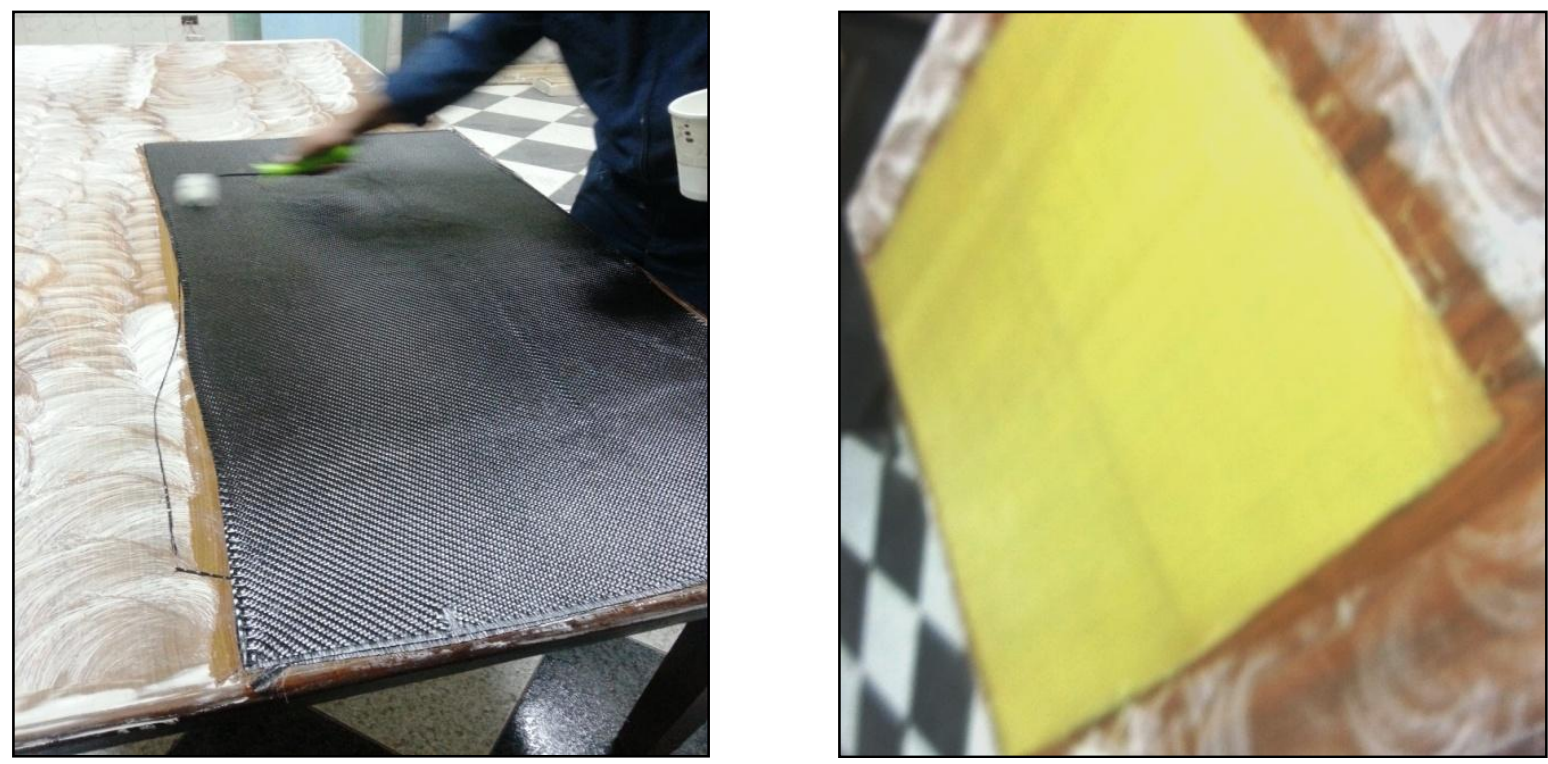

Fig. 1. Hand layup process for material fabrication

The samples are cut from the same sheet prepared with the same process to be applied in space. The samples are cut into small discs with a $6 \mathrm{~mm}$ diameter and a thickness from 1.5 to $2.5 \mathrm{~mm}$, with a minimum weight $(50 \pm 5) \mathrm{mg}$.

After manufacturing the Fourier Transform Infra-Red (FTIR) spectroscopy measurement was done in order to show the constituents of the tested materials. 
Fig.2.(a) shows the tool designed and used to cut the outgassing samples to meet the standard dimension as stated in ASTM E-595, and Fig.2.(b) shows the sample holder and collectors holder used in the testing facility of outgassing test laboratory.

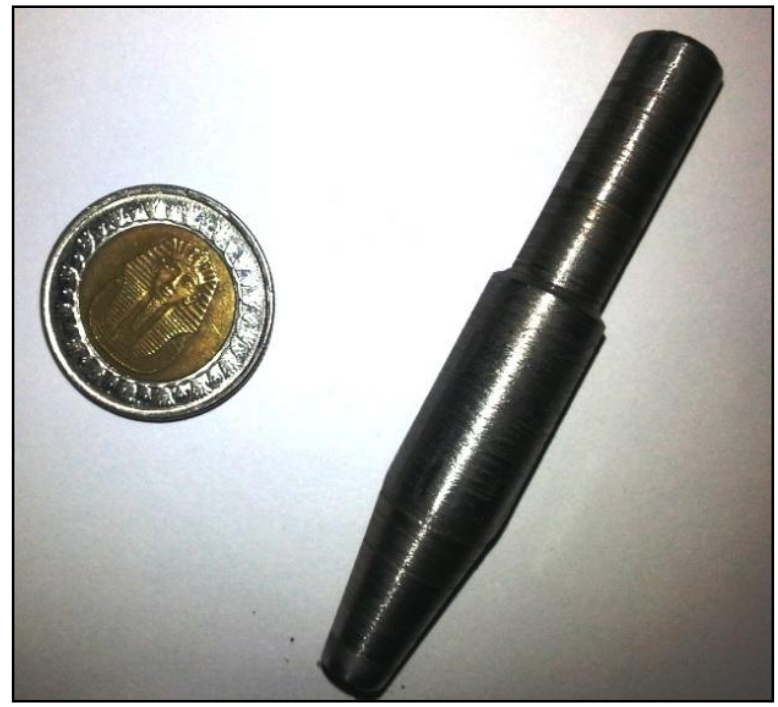

(a)

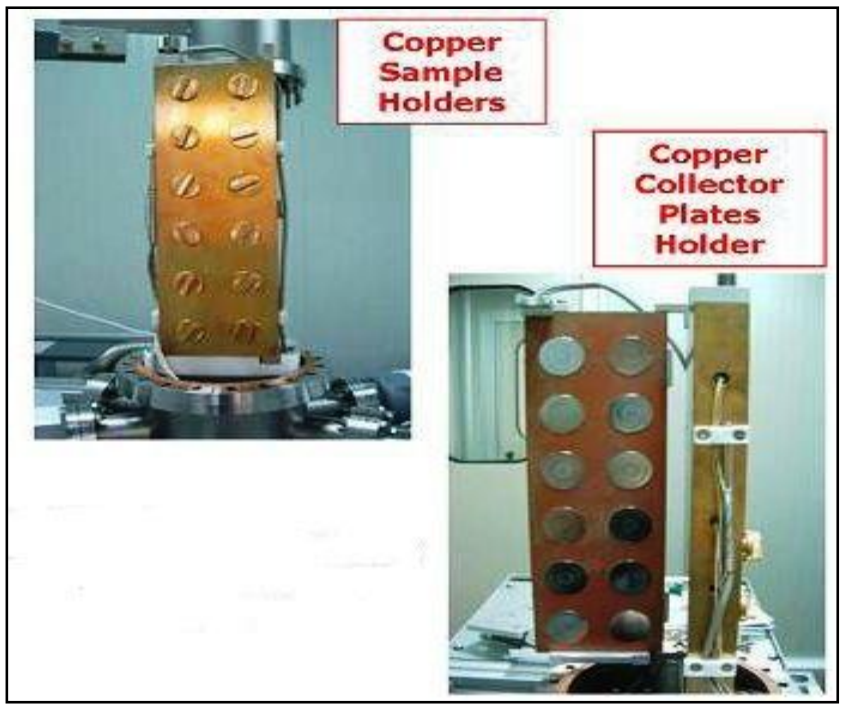

(b)

Fig. 2. (a) Sample cutting tool and (b) Sample and collector holders

\subsection{Test procedures}

In this study a ground facility for simulating the materials outgassing in Low Earth Orbit (LEO) performed in Sapienza University of Rome, Astronautics Electric and Energetic Engineering Department. After materials exposure a comparison of different structure composite materials epoxy resin matrix is presented and a confirmation of polyimide (Artilon) using in space as Multilayer Insulator (MLI). The tests performed by SASLab follows the ASTM tolerances as they are stricter than the ECSS standard

\subsection{Specifications of the facility}

The outgassing test facility is composed by a turbo-molecular pump and a cylindrical vacuum chamber. The Samples are placed in a copper sample holder and the collector plates are placed on a copper plate which is active cooled by a chiller. In Fig.3. a real photo of the outgassing ground simulator facility in the open and close configuration are showed. 


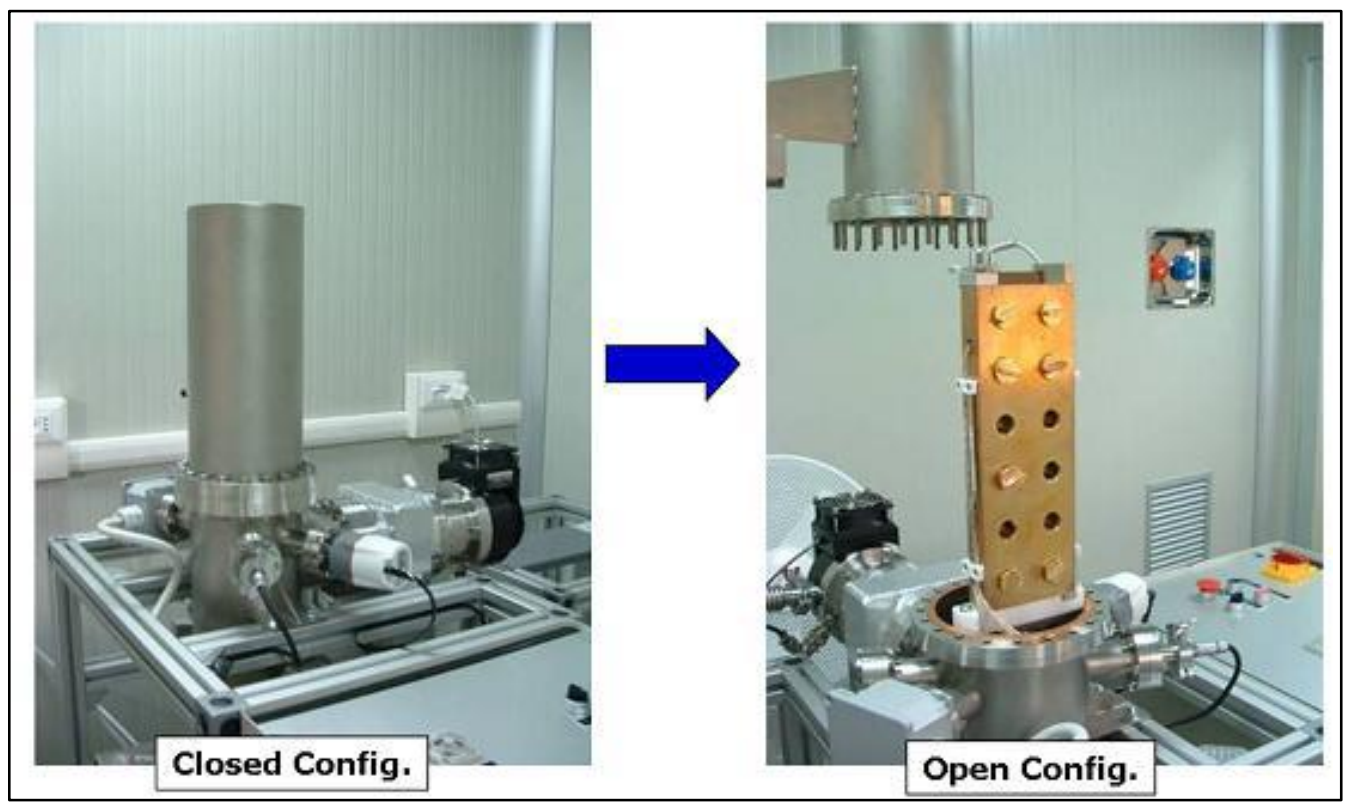

Fig. 3. Outgassing ground simulator facility configuration

\section{Operation Test Conditions}

This test method describes the test apparatus and related operating procedures for evaluating the mass loss of materials being subjected to space environment, in terms of:

\begin{tabular}{|l|l|l|}
\hline & Sample & Collector \\
\hline Temperature & ${\mathbf{1 2 5}+/-1^{\circ} \mathrm{C}}^{\circ}$ & $\mathbf{2 5}^{\circ} \mathrm{C} \pm 1^{\circ} \mathrm{C}$ \\
\hline Pressure & $10-4 \mathrm{~Pa}$. & $10-4$ Pa. \\
\hline
\end{tabular}

\subsection{Test procedures}

1. Weigh a prepared aluminum foil boat and a prepared collector plate

2. Add the test specimen (100 to $300 \mathrm{mg}$ ) to the boat and condition the sample at $50 \%$ relative humidity and $23^{\circ} \mathrm{C}$ for a minimum of $24 \mathrm{~h}$.

3. Weigh the conditioned specimen using a balance having $\pm 1 \mu \mathrm{g}$ sensitivity then place it and the boat into system.

4. Close the vacuum system and evacuate it to $7 \times 10^{-3} \mathrm{~Pa}$ or less within $1 \mathrm{~h}$, using proper operating procedures.

5. Control of the collector plate temperature at $25^{\circ} \mathrm{C}$ shall be achieved within the first hour of pump-down.

6. Maintain the collector plate temperatures at $25^{\circ} \mathrm{C}$

7. Maintain the heater bar temperature at $125^{\circ} \mathrm{C}$ for $24 \mathrm{~h}$, This causes vapor from the heated specimen to stream from the hole in the specimen compartment. then close the high vacuum valve to the pumping system and turn off the heater bar current.

8. Open the vent valve and backfill with clean, dry nitrogen regulated within a gage pressure range from 10 to $30 \mathrm{kpa}$ above atmosphere to cool the bars rapidly. 
9. Allow the heater bar to cool sufficiently to permit handling, and then turn off the collector-plate heat exchangers return the vacuum chamber to room pressure using the clean, dry nitrogen, and open the chamber.

10. After specimens have cooled to approximately room temperature, remove and weigh each specimen within 2 min of its removal from the desiccators.

11. Return the foregoing samples to the relative humidity chamber for $24 \mathrm{~h}$ in order to determine the WVR. Weigh the conditioned specimens

\section{Results and Discussions}

The test results of the outgassing values represent in four values which are abbreviated as TML\%, CVCM\%, WVR\%, and RML\% as listed in Table 1.

The outgassing test is performed at two samples for each material. The values counted are the calculated mean value.

As the manufacturing method for the tested materials is the Hand layup method without Autoclave curing which is considered as a commercial material and non-expensive method compared with the auto-clave curing method. Auto-clave method is used to remove humidity from the manufactured materials.

Table 1 Results of the outgassing test

\begin{tabular}{|c|c|c|c|c|c|c|c|c|}
\hline $\begin{array}{l}\text { Material } \\
\text { Name }\end{array}$ & $\mathrm{S} / \mathrm{N}$ & $\begin{array}{c}\text { Sample } \\
\text { Weight } \\
\text { (mg) }\end{array}$ & $\begin{array}{c}\text { Sample } \\
\text { Weight } \\
\text { After test } \\
\text { [2 min] } \\
(\mathrm{mg})\end{array}$ & $\begin{array}{l}\text { Sample } \\
\text { Weight } \\
\text { After test } \\
\text { [24 hr.] } \\
(\mathrm{mg})\end{array}$ & TML \% & CVCM \% & WVR \% & RML \% \\
\hline \multirow{3}{*}{ CF/EPOXY } & A1 & 73.851 & 71.607 & 71.269 & 3.038551 & 0.0934314 & -0.457678 & 3.4962289 \\
\hline & $\mathrm{A} 2$ & 71.488 & 69.921 & 70.278 & 2.191976 & 0.0727395 & 0.4993845 & 1.6925918 \\
\hline & $\mathrm{Am}$ & & & & 2.6152635 & 0.0830854 & 0.0208533 & 2.5944104 \\
\hline \multirow{3}{*}{ GF/EPOXY } & B1 & 93.84 & 91.629 & 92.093 & 2.356138 & 0.2131287 & 0.4944587 & 1.8616795 \\
\hline & B2 & 89.239 & 86.945 & 87.425 & 2.570625 & 0.2095496 & 0.5378814 & 2.0327435 \\
\hline & $\mathrm{Bm}$ & & & & 2.4633815 & 0.2113392 & 0.5161701 & 1.9472115 \\
\hline \multirow{3}{*}{$\begin{array}{l}\text { Kevlar/ } \\
\text { EPOXY }\end{array}$} & $\mathrm{C} 1$ & 44.206 & 41.025 & 41.755 & 7.195856 & 0.7849613 & 1.6513595 & 5.5444962 \\
\hline & $\mathrm{C} 2$ & 46.11 & 42.863 & 43.482 & 7.041856 & 0.4662763 & 1.342442 & 5.6994144 \\
\hline & $\mathrm{Cm}$ & & & & 7.118856 & 0.6256188 & 1.4969008 & 5.6219553 \\
\hline \multirow{3}{*}{ Polyamide } & D1 & 88.363 & 87.399 & 87.425 & 1.090954 & 0.3191381 & 0.0294241 & 1.0615303 \\
\hline & $\mathrm{D} 2$ & 84.833 & 84.279 & 84.286 & 0.653048 & 0.3984299 & 0.0082515 & 0.6447962 \\
\hline & Dm & & & & 0.872001 & 0.358784 & 0.0188378 & 0.8531633 \\
\hline
\end{tabular}


Figure 4.a shows the relation between the mean values for tested parameters and indicted in the $\mathrm{X}$ axis for the polyamide sample where the $\mathrm{Y}$-axis is the percent of change (\%).

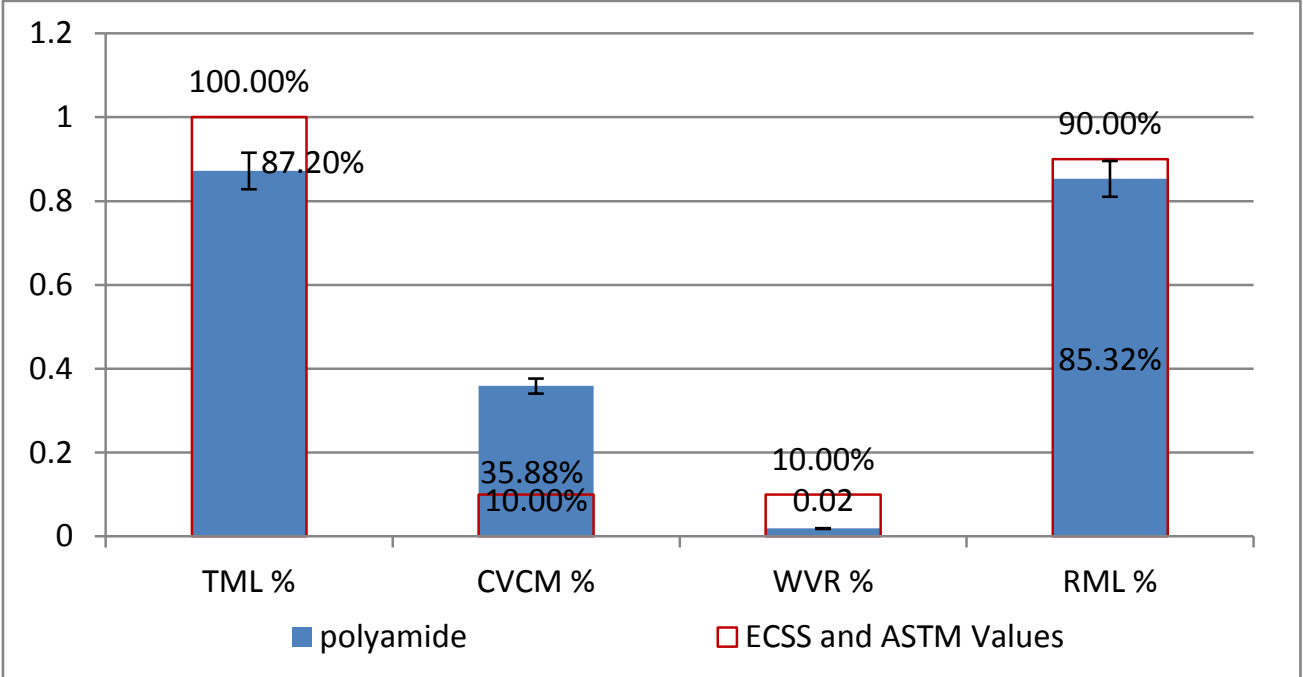

(a)
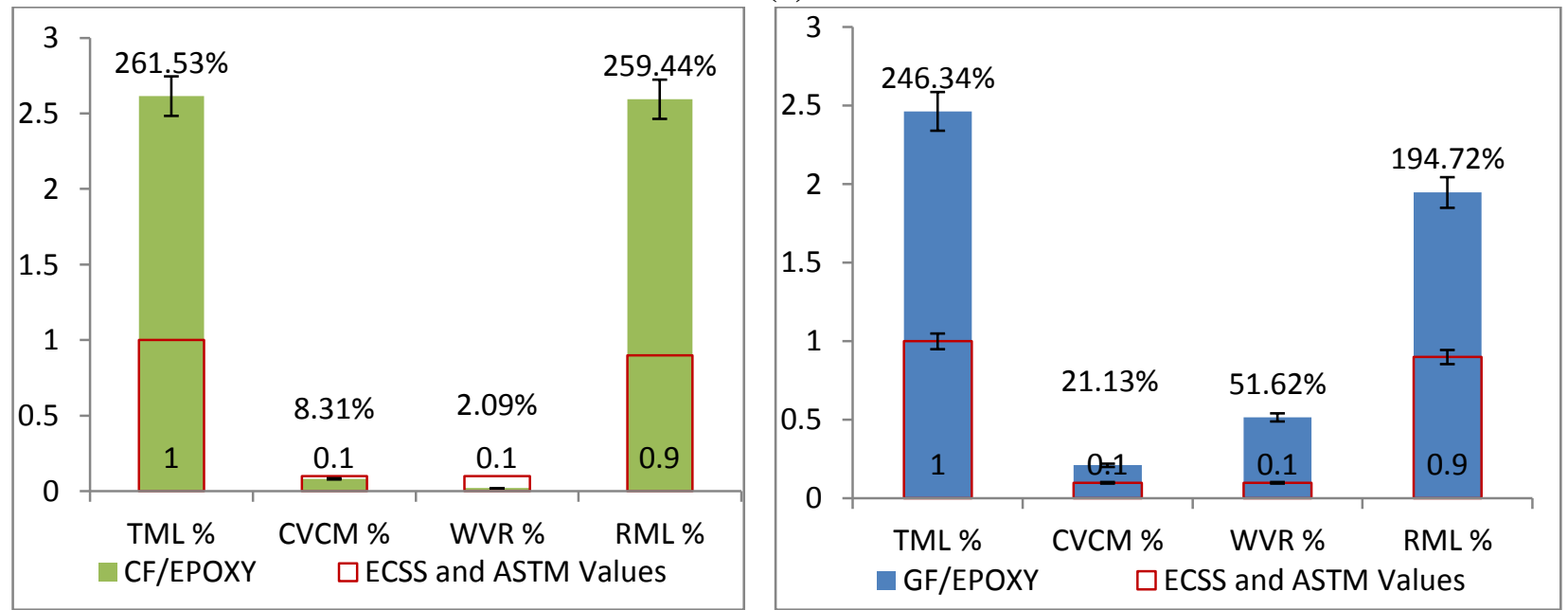

(b)

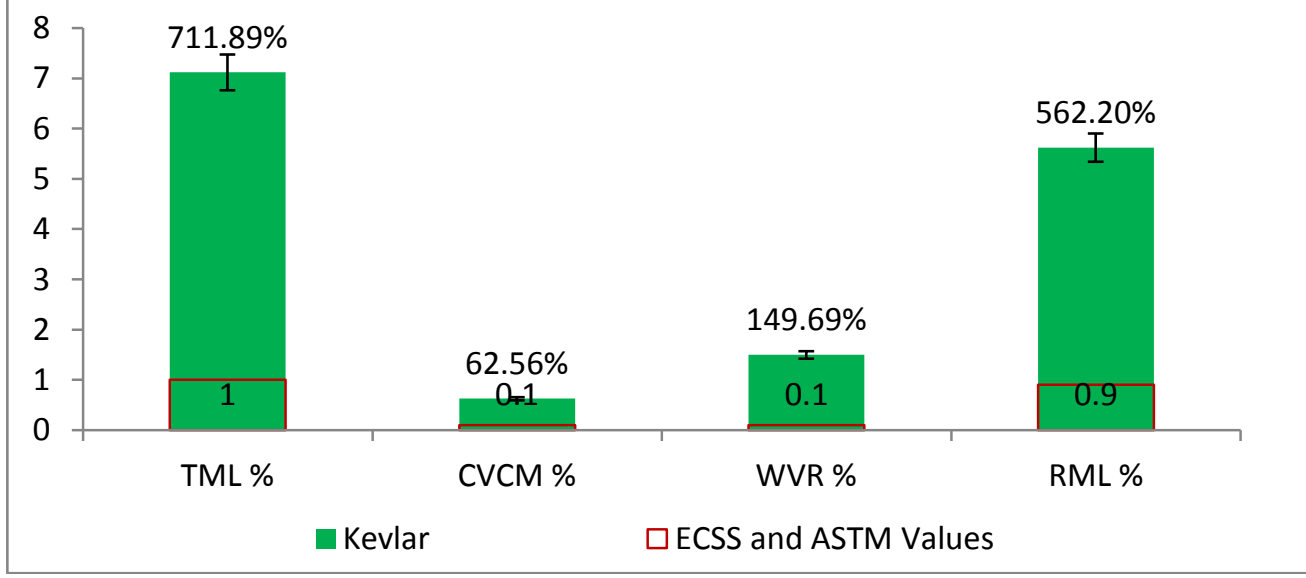

(c)

Fig. 4. (a) Polyamide test results, (b) CF/Epoxy and GF/Epoxy test results, and (c) Kevlar/Epoxy test results 
In this figure the value of TML\% is $(0.872001 \%)$ which is less than $1 \%$ it is indicating that the polyamide sample is confirmed to be used in spacecraft manufacturing materials to be exposed to the vacuum space condition. In spite of CVCM \% is $(0.358784 \%)$ which is more than $0.1 \%$ the use of polyamide is allowed because the location of this material is far away from the sensitive optical elements. WVR\% and RML\% are lower than the ECSS and ASTM values for space materials. During the test the polyamide shows weak behavior towards the high temperature because of that the used of it as an insulation of Multilayer insulation from the lower temperature side is optimum.

the common used polyamide used in space are two types of polyamide in many forms the first is polyamide epoxy and the second and most popular is Kapton which uses in many forms, The tested material in this study is Artilon, it will be the first time tested for space prove.

Table.2 Space qualified used polyamide family range [15]

\begin{tabular}{l|l|l|l}
\hline \hline Parameter & TML\% range & CVCM\% range & WVR\% range \\
\hline Value & $0.86-3.38$ & $0.05-1.39$ & $0.14-1.12$ \\
\hline \hline
\end{tabular}

Figure 4.b shows the relation between the mean values for the tested parameters and indicted in the $\mathrm{X}$-axis for the $\mathrm{CF} /$ Epoxy and GF/Epoxy samples. In Fig 4(b) the relation between two samples carbon fiber and glass fiber and the ECSS and ASTM values, it shows that the mean values of TML and RML in both carbon fiber and glass fiber are higher than the ECSS and ASTM values by the high content of humidity due to the method of manufacturing the sample without auto-clave cure. This high content of humidity does not prevent the use of these materials in space because the location of the materials are far away from the sensitive elements and these materials are used with shield cover them. On other hand, the mean values of CVCM\% and WVR\% for both carbon fiber and glass fiber are lower than ECSS and ASTM values this can be explains by the absence of the condensate materials which is harm for the optical surfaces.

Table.3 Space qualified used CF/Epoxy and GF/Epoxy range [15]

\begin{tabular}{l|l|l|l}
\hline \hline Parameter & TML\% & CVCM\% & WVR\% \\
\hline CF/Epoxy & $0.6-1.2$ & $0.01-0.03$ & $0.1-8.83$ \\
\hline GF/Epoxy & $1.07-3.50$ & $0.1-1.16$ & $0.0-0.61$ \\
\hline \hline
\end{tabular}

Figure 4.c shows the relation between the mean values for the tested parameters and indicates the $\mathrm{X}$-axis for Kevlar/Epoxy sample. According to the test performed in this study the Fig.4.c shows that the TML\% value is $(7.11 \%)$ which is very high with respect to the ECSS and ASTM values(less than $1 \%)$. the CVCM\% in this study test is $(0.6256188 \%)$ which is very high with respect to the ECSS and ASTM values (less than 0.1\%). Kevlar is a popular material used in spacecraft manufacturing, due to the NASA outgassing online database[15] the common data for space qualified used Kevlar/Epoxy are as follows:

Table. 4 Space qualified used Kevlar/Epoxy range [15]

\begin{tabular}{l|l|l|l}
\hline \hline Parameter & TML\% & CVCM\% & WVR\% \\
\hline Value & $1.86-1.92$ & 0.1 & $1.26-132$ \\
\hline \hline
\end{tabular}


The FTIR spectroscopy shows the constituents of the tested materials shown in fig 5. this figure will be used to clarify the reason of the outgassing test results. First the vertical dashed line indicates the peak at $\left(3378 \mathrm{~cm}^{-1}\right)$ this peak value is repeated at carbon fiber, glass fiber, and Epoxy. It is an indication of the presence of $(\mathrm{O}-\mathrm{H})$ bond which changes to $\mathrm{H}_{2} \mathrm{O}$ under space vacuum and temperature. This peak value does not shown up in the polyamide and Kevlar curves. The dotted line indicates the peaks about $\left(1026 \mathrm{~cm}^{-1}\right)$ this peak is repeated at carbon fiber, glass fiber and epoxy. It is indicating the presence of $(\mathrm{C}-\mathrm{O})$ bond. This peak does not appear in polyamide and Kevlar curves. Due to space temperature fluctuation and space vacuum the water vapor and carbon dioxide gases released. According to ECSS the water vapor and carbon dioxide is not seen as a critical gas and not to prevent the use of these materials in space. [7,9]. Since the FTIR for Kevlar does not show the $(\mathrm{H}-\mathrm{O})$ or $(\mathrm{C}-\mathrm{O})$ peak so the released gasses may be harmful and cause surface contamination. The unknown gasses with the high percentage may lead to dimensions instability and properties degradation.

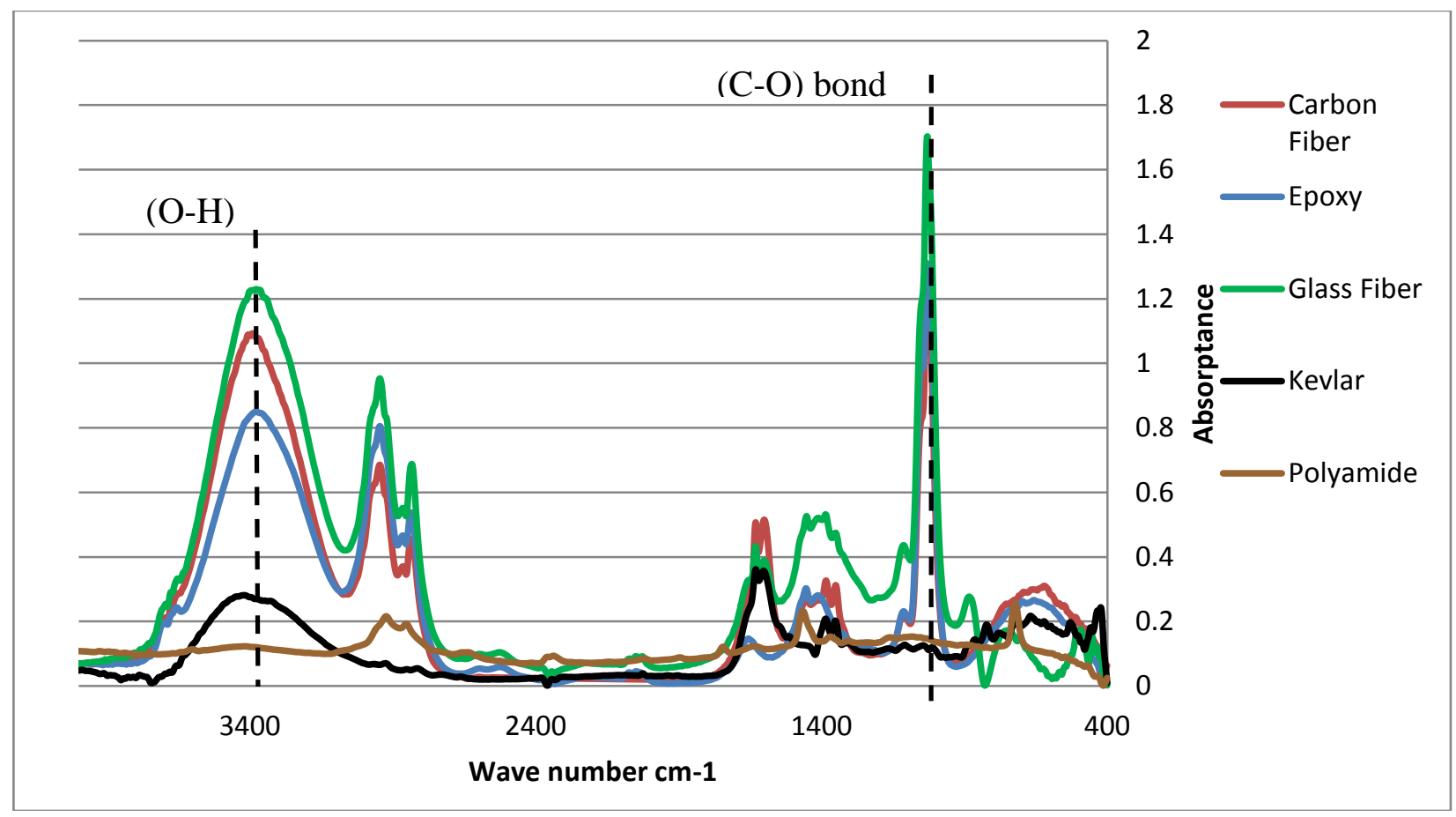

Fig. 5. FTIR of the used materials

\section{Conclusion}

This study shows the effect of outgassing on the composite materials made by a hand layup process without auto-clave curing which is low cost commercial method. The test results values of TML\% and CVCM\% for the Carbon fiber/ Epoxy and Glass fiber / Epoxy indicated higher values than standard acceptance values but still accepted because the material location in the spacecraft is far from the sensitive items and the outgassing components are not critically $\left(\mathrm{H}_{2} \mathrm{O}\right.$, $\mathrm{CO}_{2}$ ) according to ECSS, and these materials are used in structure manufacturing and shielded with an insulation materials. These show the possibility of using CF/Epoxy and GF/Epoxy in spacecraft manufacturing in spite of the values are little higher than standards.in the Kevlar/Epoxy the result values of TML\% and CVCM\% are very high compared by the standard 
acceptance values therefore the use of hand lay-up Kevlar/epoxy in the spacecraft manufacture is rejected. The Polyamide (Artilon) Sample test results are confirming that the Polyamide material is accepted in use in space with proper values according to standards. This material is confirmed as a new material used in spacecraft as a layer in the multilayer insulation at the lower temperature side.

\section{References}

[1] Joo-Hyun Han, Chun-Gon Kim, "Low Earth Orbit Space Environment Simulation and Its Effects on Graphite/Epoxy Composites", Composite Structures, 72(2006), 218-226.

[2] Tribble AC., "Designing For The Space Environment", Aerospace Am 1993:26-9.

[3] E. Grossman, I. Gouzman, "Space Environment Effects on Polymers in Low Earth Orbit", Nuclear instruments and methods, B208 (2003), 48-57.

[4] Jae-Sung Kwon, Haeyong Jung, In Seok Yeo, Tae-Ho Song, "Outgassing Characteristics of a Polycarbonate Core Material for Vacuum Insulation Panel", Vacuum, 85(2011), 839-846.

[5] E. Grossman, I. Gouzman, "Space environment effects on polymers in low earth orbit", Nuclear Instruments and Methods in Physics Research, B 208 (2003), 48-57

[6] M. Hassig, K. Altwegg, H. Balsiger, "Spacecraft Outgassing, A Largely Underestimated Phenomenon", Space Sci. Rev. 128(2008), 745-801.

[7] K. Fayazbakhsh, A. Abedian,"Materials Selection for Application in Space Environment Considering Outgassing Phenomenon", Advances in space research, 45(2010), 741-749.

[8] ECSS-Q-70-71A rev.1, "Space Product Assurance, Data for selection of Space Materials and Processes", ECSS Secretariat ESA-ESTEC Requirements and Standards Division, 18 June 2004.

[9] Marta Albano, Andrea Delfni, Fabrizio Volpini, Mario Marchetti, "Outgassing Test Report", SASLab, Sapienza university of Rome,2014

[10] ASTM standard E 595, 'Standard test methods for Total Mass Loss and Collected Volatile Condensable Materials from Outgassing in Vacuum Environment", 1999.

[11] Department of defense, 'composite material handbook: polymer matrix composites guidelines for characterization of structural materials', MIL-HDBK-17-1F vol. 1, Department of defense. Washington, DC; 2002.

[12] Sang Yoon Park, Heung Soap Choi, Won Jong Choi, Hyuk Kwon,"Effect of vacuum thermal cyclic exposures on unidirectional carbon fiber/epoxy composites for low earth orbit space applications", Composites: Part B, 43 (2012), 726-738.

[13] Martin, D.J., Carl, R.M. "The influence of commonly used materials and compounds on spacecraft contamination". Acta Astronautica, 30(1993), 51-65.

[14] R. Destefanis, E. Amerio, M. Briccarello, M. Belluco, M. Faraud, E. Tracino, C. Lobascio, " Space Environment Characterization Of Kevlar®: Good For Bullets, Debris And Radiation Too"

[15] http://www.outgassing.nasa.gov/cgi/uncgi) 